nen Gruppenreactionen aufgeführt und dann zur Trennung der Gruppen und der einzelnen Gruppenglieder geschritten. Die Prüfung auf Säuren, ein Anhang über das Verhalten der Verbindungen seltener Flemente und einige Uebungsbeispiele bilden den Schluss des Werkes, welches hiermit den Herren Collegen bestens empfohlen sei.

Geseke.

Dr. Carl Jehr.

\title{
Die Analyse und Verfälschung der Nahrungsmittel von
} James Bell, Director vom Somerset House Laboratorium, Vicepräsident des Institute of Chemistry. Uebersetzt von Carl Mirus. Mit einem Vorwort von Prof. Dr. Eugen Sell. I. Band. Berlin 1882. Verlag von Julius Springer.

Vorliegender erster Band, dem noch ein zweiter und dritter folgen soll, umfasst die Untersuchungen von Thee, Kaffee, Kakao, Zucker und Honig und hat besonders deshalb Interesse für die Nahrungsmittelchemiker, weil die in demselben aufgeführten aualytischen Zahlen zum grössten Theil Originalzahlen sind, die dem Laboratorium des Verfassors entstammen, worin schon seit geraumer Zeit Untersuchungen von Nahrungs- und Genussmitteln ausgeführt wurden.

Die Sprache könnto eine etwas knappere sein, auch würde man in einem derartigen Werke Angaben über den Ursprung, die Eigenschaften etc. etc. der betreffenden Nahrungs - resp. Genussmittel gern entbohren. Anerkennenswerth ist es, dass die mikroskopisehe Untersuchung gebührend berücksichtigt und durch gute in den Text gedruckte Abbildungen erläutert ist.

Geseke.

Dr. Carl Jehn.

Deutsche Flora. Pharmaceutisch-medicinische Botanik. Ein Grundriss der systematischen Botanik zum Selbststudium für Aerzte, Apotheker und Botaniker von H. Karsten, Dx. der Phil. und Med, Prof. d. Bot. Mit gegen 700 Holzschnittabbildungen. Berlin, C., 1882. J. M. Späth. Siebente Lieferung. 96 S. gr. 8. Preis: 1 M. 50 Pf.

Vorliegende 7. Lieferung dieses ausgezeichneten Werkes reicht von „Canellaceae" bis "Mimosaceae " und behandelt unter anderen Familien auch die artenreichen Cruciferen und Papilionaceen, von ausschliesslich exotischen Familien folgende: Canellacea , Clusiaceae, Dipterocarpeae, Bixaceae, Passifloraceae, Dat iscaceae, Moringaceae, Caesalpiniaceae. Es gereicht uns zu hoher Freude, das Lob, welches wir gleich von Anfang an diesem ebenso streng wissenschaftlichen wie wahrhaft populären Werke gespendet haben, auch von anderer und weit competenterer Seite getheilt zu sehen.

Dr. Karl Müller von Halle ist es, welcher in seiner "Natur" (1882, No. 20, S. 242 und 243) eine ausführliche Besprechung dieser "Deutschen Flora" widmet und sogar 5 Holzschnitt-Tafeln aus derselben reproducirt, um den Lesern der "Natur" zu zeigen, wie es dem Verf, nicht allein auf Ansicht, sondern auch auf Einsicht ankommt. "Gerne bekennen wir", schreibt Dr. Karl Müller, "dass es sich hier um ein Werk handelt, welches nicht mit gewöhnlichem Maassstabe gemessen werden kann. Zwar ist der Kern seines Inhaltes ein floristischer, allein der Verfasser fasst diese vaterländische Floristik im grossen Stgle an, wie es soit langer Zeit in solcher Weise nicht mehr geschah. Wenn es sich auch zunächst um die deutsche Flora handelt, so geht der Zweek 
des Verf. doch offenbar dahin, jene Flora als einen Bestandtheil der Gesammt Vegetation unseres Planeten zu fassen, sie mit den Formen derselben in Verbindung, in Vergleich zu stellen. Daraus geht dann ganz von selbst hervor, was die deutsche Flora ist und nicht ist, welche Lücken sie ausfüllt oder an sich trägt. So erwirbt sich diese "Deutsche Flora " Karsten's von vornherein einen kosmischen Charakter, wie sich das auch von einem Manne erwarten liess, der zwölf Jahre lang vom äussersten östlichen Küstengebirge des äquatorialen Südamerika bis zu dessen Riesen-Höhen botanisirend wanderte, um auf der ITochebene von Quito zu den beträchtlichsten Erhebungen des wunderbar gegliederten Festlandes empor zu steigen. Wer seine grosse "Flora Columbiae" näher kennt, und wer, wie wir, im Besitze eines grossen Theiles seiner dort gesammelten Pflanzenschätze ist, der weiss es auch, dass dieser Mann zu den fleissigsten, umsichtigsten und kenntnissreichsten unserer heutigen Botaniker, sowohl im systematischen, wie im morphologisehen und physiologischen Sinne, gehört.

Selten nur vereinigen drei solcher Eigenschaften sich in einem einzigen Beobachter, und das ist es auch, was ihn und sein Werk in die vordersten Reihen stellt...." - So sei die "Deutsche Flora" abermals aufs Wärmste empfohlen!

\section{A. Getreeb.}

\section{La España científica y agricola.}

Unter diesem Titel erscheint seit diesem Jahre in Madrid eine für gebildete Landwirthe und Gutsbesitzer bestimmte Wochensehrift, welehe ausser einer allgemeinen Wochenübersicht und einem belletristischen Theil in ihren als "Seceion científica" und "Seccion teórico-práctica" bezeichneten Abschnitten gut gewählte naturwissenschaftliche Aufsätze bringt. Die vorliegenden Nummern 19 und 20 enthalten so z. B. Artikel über "die rationelle und die empirische Methode in den Naturwissenschaften ", "die Ackererde “, "Liebig's Einfluss auf die Naturwissenschaften " und über "Regengüsse und "Ueberschwemmungen." Typographisch ist das Blatt recht sehön ausgestattet, auch mit Holzschnitten geziert, und besitzt etwa das Format der Leipziger Illustrirten Zeitung.

Dr. Vulpius.

\section{Landläufige Irrthümer über die Impfung.}

Unter diesem Titel hat das englische Parlamentsmitglied P. A. Taylor einen offenen Brief an den für obligatorische Impfung wirkenden Dr. Carpenter gerichtet und denselben in einer 200000 Exemplare starken zweiten Auflage jüngst erscheinen lassen; auch in andere europäisch $\theta$ Sprachen ist er übertragen worden.

Vor zehn Jahren war der Verfasser Mitglied der vom englisehen Parlamente eingesetzten Enquête-Commission in Betreff der Impfung und damals auch Mitunterzeichner des für die Impfung sich aussprechenden Commissionsberichtes.

Inzwischen ist er aus einem Saulus ein Paulus geworden, hat die Ueberzeugung gewonnen, dass das ganze Impfinstitut ein Aberglaube und ein Irrthum ist, und zwar ein sehr gefährlicher und verhängnissvoller. Er betrachtet es daher als eine heilige Pflicht, so viel als an ihm liegt, den Fehler wieder gut zu machen, welchen er nach seiner heutigen Auffassung durch Mitunterschrift jenes Commissionsberichtes begangen hat. Die vierzig Seiten starke Abhandlung ist 